\section{Construction of Identity in Globalized Milieu: A New Paradigm}

\author{
Manju Sharma
}

\section{Abstract}

In anthropological perspective, identity is taken from the two opposite angles; uniqueness and sameness. Uniqueness keeps the properties, which make a person distinct from the others. Sameness keeps the qualities that a person is associated with others, with groups or categories on the basis of some salient common features. This article analyzes how individual or group identity is created, reshaped and molded after physical mobility of the people, what plays roles in creating identity, what values for that, and how it can be institutionalized. The paper concludes that immigrants' identity is constructed through the interaction among the rapidly increasing global inflows of knowledge; their own previous worldviews; the new social cultural patterns of host country; norms and values of other surrounding immigrants, and the perception of external pressure. In the process of cultural mixing, there is possibility of cultural homogenization and cultural heterogenization. Similar worldviews make the people nearer to each other which broaden the circle of 'us' and hence can lead toward homogenization of culture. On the other hand, dissimilarities in worldviews increase the level of 'them' therefore leads towards heterogenization.

Keywords: Cultural homogenization, Cultural heterogenization, Globalization, Identity, Social reality, Worldviews

\section{Introduction}

Globalization, a borderless concept of interaction and integration which creates the interdependence and interconnectedness, is the most spread out, discussed, and even debatable subject in the contemporary world. Although it is developed from the historical past, it is considered as a thought of post-modernity which is accelerated by rapidly growing media, communication technology, transport and so forth. Globalization has many dimensions for example; social, economical, political, cultural, financial, environmental, and so on. However, social, economical, political and cultural aspects are highly focused in literature, media, and academia therefore they are considered as the main pillars of globalization.

The social dimension refers to the impact of interconnectivity on the life and work of people on their societies and families. Economic dimension refers to the global interconnectedness of market, finance, labor, trade, investment, and so on. Political globalization refers to the increasing number and power of human associations which influence and govern the world as a whole. It also relates to the political interaction of transnational actors that affect more than one nation, state or region. Cultural dimension, which is concerned area of anthropology, refers to the transmission of ideas, values, and meanings across the national borders. Here, the commodities and ideologies become standardized around the world. Mass consumption of cultural commodities facilitates to globalize the culture. In connection to migration, anthropology has keen interest on people's identity. However, a set of shared questions for example why people move, who moves and what happens after a move is considered in all disciplines for example, political scientists and economists are largely interested in flows of migrants and how these flows are shaped by policy, labor and markets or trade agreement. Sociologists largely focus on the integration, how migrants can be integrated in the social, cultural, legal, and technological systems. But different from these aspects, anthropologists highly concentrate on the issues of what they get themselves and feel in a new place, how they frame themselves and are framed by others in different land, what is important for them, how they are connected to their homeland, relatives and families and so on. Since an increasing number of people interact at new levels of intensity, they might urge to reformulate their identity with relation to other. At that time culture might be assimilated or accommodated in the process of integration or there might also be stronger feeling of own cultural identity after the migration. 
Moreover, globalization has a massive impact on the teaching and practice of social anthropology. The anthropological method, like kinship or religion that previously used, is becoming insufficient and weak to address the complex society. As anthropology does not only limit on how cultural commodities are being produced, consumed and transmitted, it has also a keen interest on how individual or group identity is created, reshaped and molded after physical mobility of the people all around the world, what plays roles in creating identity, what values for that, and how it can be institutionalized. To tackle the increasing complexity it is needed to address the theoretical as well as methodological problems that the globalization has brought. Therefore, today's complex society demands multiple methods and approaches to extract the focused subject of anthropology. Hence, the scope and dimensions of anthropology are increased. This paper describes some emerging paradigms which can be used to explore the identity of immigrants. Further, it focuses how immigrants' identity is built and what are the key factors that play role for formation of the identity.

\section{Developing issues of identity in globalization}

In the early days, before 1950s, an anthropologist's interest in a person was reflected in the concept of personality. The relationship between culture and personality was the object of research in American anthropology. Erik Erikson's work in 1950 on "Ego Identity" is one of the best-known theories of personality in psychology which was also used in the anthropological research. Erikson's theory describes the impact of social experience in personality and examines the psychological conditions that influence the adjustment of human personality (Erikson, 1950). So, psychology is created and moulded on the one hand and personality is the reflection of one's psychology on the other. Later, the concept of personality is replaced by identity and entered in anthropology as a key term (Meijl, 2008). Identity refers primarily to a coherent sense of self or the feeling of being the same. It keeps sense of how one is viewed and identified by the other(s). So, identity is a well-adjusted personality that emerges from the same, or from the identical. In another word, it is an identification of self by self and other. It keeps the answer who I am or who we are in the global context. In the globalizing process of cultural mixing, the concept and scope of identification is broaden, elaborated, modified and refined.

With the development of capitalism, basically since the end of 19th century, a greater geographical mobility made people's participation in larger social systems, interaction in greater cultural diversities, and communication with varieties of language and technologies which has created cultural complexity. Therefore, there is a great debate and discussion on whether the recent pour of cultural flows and global consciousness increase or decrease the sameness between the people around the world. The tension between cultural homogenization and cultural heterogenization is becoming the most controversial issue for the interpretation. Homogenization is generally understood as a process which leads towards uniformity. Some theorists (Stiglitz, 2007; Bauman, 1998; Beck, 2000) argue that globalization has created domination by western culture all over the world. They describe it as a cultural imperialism and new form of colonialism. On the other hand, practitioners have been worried about disappearance of cultural variation or cultural heterogenization. They insist to widen the scope of anthropology and argue that the study of cultural variation should be the main aim of modern anthropology. From the birdeyes view, we might see the culturally homogenized world but if we see through the anthropological eyes, we can find cultural differences or the heterogenized world. Therefore one of the today's leading anthropologists, Erik Hylland Eriksen suggests to look more closely at the 'cultural globalization'. Cultural globalization does not necessarily mean that we all are becoming identical rather we all are becoming different (Eriksen, 2001). Hence, anthropology has an extra responsibility to explore the issues of cultural homogenization and heterogenization which might be found differently in different place and people. What plays role to be homogenized or heterogenized culture is also a subject matter of anthropology.

\section{Identity: a theoretical discussion}

In anthropological perspective, identity is taken from the two opposite angles, uniqueness and sameness. Uniqueness keeps the properties, which make a person distinct from all others. We 
cannot speak for a long about one's experience without speaking about others. Sameness keeps the qualities that a person is associated with others, with groups or categories on the basis of some salient common features. It is a process, not a thing. It is not something that one can have, or have not; it is something one does (Jenkins 2008). It is not something that we think about; it is something we think with (Gillis 1994) for examples, we can take ethnic identity and identity of nationalism. People use it to sort out themselves and their fellows individually and collectively. Human worldview which is discussed below in formation of identity helps to determine us and them; key terms to determine collective identification. It is about judgment of social reality; how a person sees the world, judges the other, expresses emotions, and so on. Similar worldview broadens the circle of $u$ s which is also a symbol of cultural identity. Cultural identity can be taken in terms of common shared norms, values, social order, and behavior; a sort of collective common self. It refers to the common collective identification that creates a common culture among participants concerned where the self-concept is derived from the membership in social groups. It claims that group processes and inter-group relationships affect significantly on individuals' self-perception and behaviors. The group to which a person belongs provides one's definition of who s/he is and how s/he should behave in the social context as a member of the group.

In a broader way an anthropologist, Eriksen (2004) has categorized identification into social, cultural, relational and situational, and imperative and chosen. These categories provide insight of theoretical knowledge on how identification formulates and what would be the enforcing factors for that. Social identification relates to which groups a person belongs to, who he or she identifies with, how people establish and maintains invisible but socially efficient boundaries between us and them. It gives a sense of belonging to a complex society. Language, locality, kinship, nationality, ethnic membership, family, age, education, political views, sexual orientation class, religion and gender could be more possibilities of group identification. In some society, caste, clan and kinship might be valuable for identification and others might be important for national identity and professional identity. In some cases and situations, gender identification might give a sense of group difference whereas in the other cases and situations, profession might keep value of sameness. Cultural identification is highly related to ethnic identification, which was entered in anthropology at the end of 1960s (Eriksen, 2004). There are many ethnic groups with great cultural variation whose mutual cultural differences are difficult to point out from outside. To identify the difference, we need to do an anthropological study applying different tools and techniques. For example, to find out existence relationship between/among the groups or to identify how the groups perceive differences between/among them, negative stereotype approaches may be important. For instance, some militant radical feminist might hold that all men are against women; militant right-wing Europeans may hold that all immigrants are either welfare parasites or religious imperialists.

Relational and situational identifications vary on the basis of the relation and situation. It is well described by sociological role theory, which emphasizes that each and every person can be many persons depending on the situation. Barth's (1966) famous model of ethnicity presents that ethnic identity is both enforced and chosen which logically seem impossible. One can rarely be entirely free from oneself if one is having imperative or enforced identification. If you are a Nepali in the United Kingdom for example, you will always be Nepali even if you want to be British. Because you cannot prevent yourself from using Nepali language and you cannot prevent many of your Nepali as well as British friends from perceiving you as a Nepali immigrant for your rest of life. In certain societies and in certain historical contexts, it is very difficult to escape from ethnic identification. It comes from outside, from the state or from the powerful groups. One cannot control it. Generally, in societies where politics are strongly ethnicized, like Mauritius, ethnic identity may be the first thing one notices and one introduces oneself. Here ethnic identity is more imperative than situational. How much of the identity package of ones' is chosen and how much of it is enforced? It is difficult to embark in a modern society. In the common sense group memberships, like kinship, ethnic identity, mother tongue and gender are imperative or enforced while others are chosen. 
Contrasts are important to identify differences from others because without others, we cannot be us. The construction of identity is preceded by recognition of difference and by an awareness of what self is not. It holds the answers of why some are more important while others are not, why one should be group member and others are not. Eriksen in his What is Anthropology gives some analytical strategies to find out the answer how certain identities become more important than others. Why ethnic identity is more important in Fiji, religious identity in Algeria, caste identity in India, class identification in many parts of Britain, national identity in Estonia, which is so weak in England and Italy. How much variations are possible in identifications within a society? The first principle is "the internal cohesion of a group depends on the degree of external pressure" (Eriksen, 2004:163) which was initially formulated by German sociologist, Georg Simmel in early twentieth century. It is very relevant in analysis as it helps to understand why group identity can be strong and weak. Why do people insist for identity? For example, why is Muslim identity becoming strong globally? Why is gender identity more often associated with women and why is small inhabitants Palestine or Israel national identity stronger than larger country like Germany or Britain? Why is 'race' more concerned with blacks than whites? It is because the members of belonging groups perceive the pressure from outside more strongly and get convinced as if they are threatened or marginalized.

\section{Formation of identity}

The global integration of communication, information networks and development in transportation are sparking off large-scale movements of labor, people and cultural meanings. Giddens (1990) states it is because of disembedding and reflexivity nature of modernity. Disembedding is the process where social relationships are detached from local binding context. Reflexivity is the way in which social practices are constantly examined and transformed in the light of intensively increasing flows of information and communication. Therefore, a key issue in social science is to explore how different and changing social and cultural contexts influence in formation of one's identity. In modernity, social and cultural processes are not in linear development, they are rather a series of discontinuous, breaks, and ups and downs which imply that society has changed, re-organized and transformed with the new principles (Giddens, 1990). Arjun Appudurai says it is because of motion of object we live in. Objects include knowledge, ideas, and ideologies, people, values and norms, goods and images, technologies and techniques. The more stable object is nation state but it is also characterized by floating populations, transnational politics within national boarders, and mobile configurations of technology and expertise. However, the flows of persons, objects, images are not coeval, convergent and spatially consistent. They have different speeds, varieties, and varied relationships to institutional structures and different regions, nations and societies (Appudurai, 2002). As human character is not entirely genetic, it is acquired through learning; this disjuncture affects human livelihoods and all aspects of human life, hence their identity. Interaction with changing new social and cultural contexts, and the way of tackling with series of ups and downs creates social order which is an identity of the people connected in.

Similarly, person's worldview guides to construct the identity in globalized milieu. Worldview is a set of assumptions about the human realities. It can be taken as the network of presuppositions through which one can understand, evaluate, and judge the reality. It is a lens through which one can see the world. Our worldview is formed by our education we get, the surroundings we grow in, the culture we live in, the literature we read, the philosophy we are influenced by, media and movies we absorb, and so forth. Therefore, the similar worldview creates similar social reality therefore it leads towards similar cultural identity. In contrast, different worldview leads towards differences. To provide insight knowledge on worldviews Hiebert (2008) has mentioned three dimensions of worldviews: the cognitive, affective and evaluative or beliefs, feeling and values respectively.

The cognitive or existential assumptions provide a culture the essential cognitive patterns: epistemological, hermeneutical, and logical - through which people explain reality. In fact, people explain reality on the basis of what they perceive. Therefore, there is a high possibility to perceive same thing differently by different people. John Fiske, renowned scholar in communication, argues that signs do not point the objective realities. They evoke 


\section{0 | Manju Sharma}

subjective images in the mind. Both word and contents of the word are arbitrary which helps to understand subjective and objective reality (Fiske, 1990). The perception is guided by person's worldview. It integrates and organizes ideas, beliefs, norms, and values. Similarly, the assumption of "self" provides people to pose themselves within the culture. For example, south Indian tribes have not got their individual self identity. Individual is recognized by the tribal group to which one relates. In western culture, it may seem ridicules if self is said to be in the core of individual identity.

Affective assumptions are about emotions, the mental and psychological state associated with feelings, thoughts, and behaviors. For example, most of Chinese may experience mouthwatering by seeing a hanging dog in front of restaurant, whereas western people may feel pain seeing the same scene. It happens because our psychological stimulations are different. Western people take a dog as a pet. Therefore, they cannot imagine a dog as food whereas for Chinese it is meant for meat. Further, for Africans and South Asian saying "dog" to someone is taken as an insult. Evaluative assumptions provide people a guideline to judge, and determine the truth and error; like and dislike; right and wrong; moral and immoral; cultured and uncultured; gentle and rough; fair and ugly; wise and foolish; and so forth. When immigrants find similar worldview in the nationals of host country, the cultures can be assimilated which leads towards homogenization of the culture.

Similarly, worldview answers our fundamental epistemological questions. For example, where are we from? Where are we going? What is wrong? What is sin? What is righteousness? What is universe? Where are we in universe? All these questions signify one's identity. For example, for the Muslim universe is a creation of Allah, we are servants of God and we are here to fulfill his wills, which are revealed in the Quran whereas for many western seculars human life is made of molecules. Therefore, a Muslim immigrant categorizes other Muslims on us and the rest on them. Therefore, similar social norms, values, and beliefs are set through the person's worldview. Berger and Luckmann (1966) say these similarities signify shared values. Higher the shared values indicate nearer to the 'us'. Therefore, naturally the similarities distinguish the 'others' and practicing them in daily life creates social order which is group identity. Similarly, worldview monitors cultural change. When we confront with various kinds of new ideas, behaviors, knowledge, and products in globalized milieu, worldview helps us to adopt those, which are similar to us and reject those, which are not. The practice of accepting and rejecting creates our identity. When our worldview no longer meets our basic needs, desires, and demands, we adopt new one. Doing all these actions, we reshape our identity.

\section{A model of 'identity' formation in globalized melieu}

The following framework answers how immigrants' identity is constructed and what are the major influential factors for that.

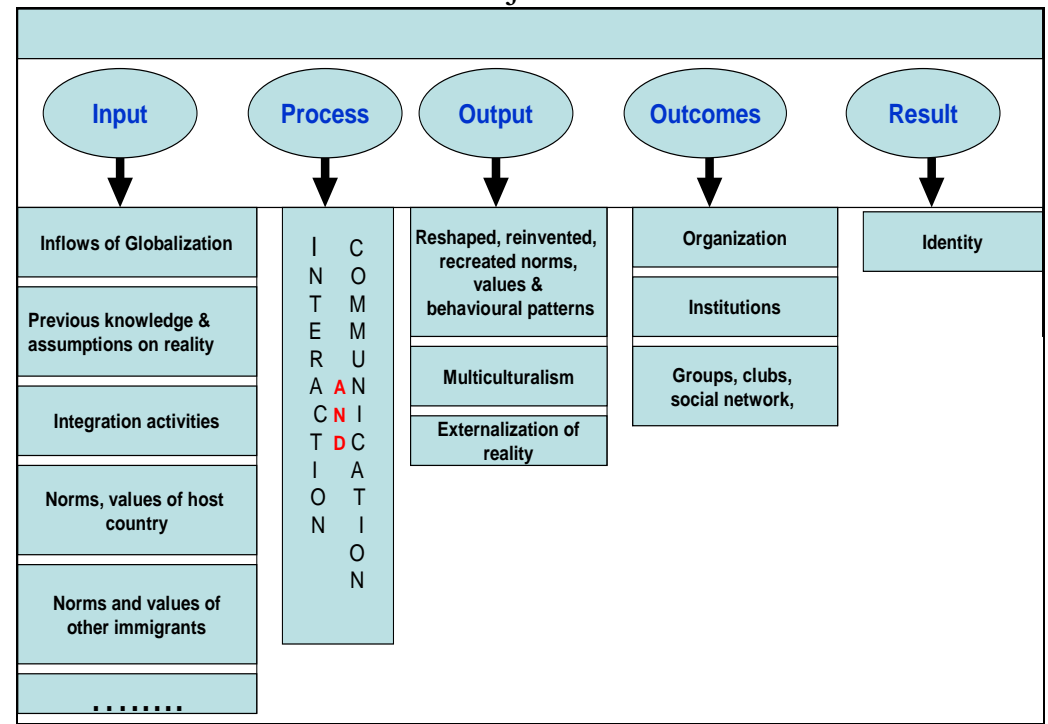

Source: (Sharma, 2012:47)

The immigrants' identity is constructed through the interaction among the rapidly increasing global inflows of knowledge; their own previous worldviews; the new social cultural patterns of host country; norms and values of other surrounding immigrants; and so on which are considered as the inputs for the process of interaction. Here process means interaction and communication among the inputs. In this process of mixing different social and cultural patterns, there could be a number of different outcomes from long- 
term encounters between or among the different groups. Eriksen (2007) says sometimes one group is ultimately absorbed into the other; sometimes it is absorbed culturally but not socially; sometime the groups merge to create a new entity; sometimes the competitive relationship occurs; and sometimes one group completely exterminates. To identify the types and level of mixing is the prime aim of today's comparative anthropology. In the course of solving problems and fulfilling needs and desires in the modern society, the new knowledge is invented, emerged and created. The previous knowledge can be reshaped, which is the output of the interaction.

The result of cultural mixing can appear in various forms; for example, cultural pluralism; hybridity; diasporic identity; transnationalism; creolization and so forth. Berger and Luckmann say those newly emerged and the reshaped subjective knowledge are shared within a community. This externalization of knowledge creates the social order in the forms of social organization, institutions, social network, objects, pictures, different cultural clubs, groups, and so forth-an objective reality (Berger and Luckmann, 1966)-which are the outcome of the interaction. It creates social order and identifies one's identity. Social order is collective shared norms of human activity, which guides human activities, behaviors and actions. The community reifies those shared knowledge in a way that they are taken as if they are real. Similarly, the cultural mixing creates the power differences between the groups involved in. Mixing at the cultural level does not exclude strengthened group identification and does not necessarily create cultural homogeneity, but it can also create a new configuration of diversity in the host country and as Arjun Appudurai (2002) states, the various metropolises in new societies try to indigenize in one or another way which signifies cultural heterogeneity.

In addition, identity is the collective reflection of one's perception on social reality. Social reality is not an absolute fact, as natural science has to be. It is socially constructed in the process of interaction with others. Berger and Luckmann (1966) explain that our understanding of the social world is shared understanding which is created and maintained through daily social interactions and communications. Socially constructed knowledge appears in the form of beliefs, shared values and social norms. They further mention that man together with other produces a human environment, with totality of its socio-cultural and psychological formations. It is impossible for man to develop as man in isolation, therefore human means itself within the realm of social. Social reality is not only the subjectively meaningful conduct of people's lives; it is an objective reality which is produced by human. Therefore, social reality must be understood both subjectively and objectively. For that, one should view society in terms of "ongoing dialectical process composed of the three moments of externalization, objectification, and internalization" (Berger and Luckmann, 1966:129). From these three phases, people interact with a social world. Scott (2001) describes, Externalization is the production in social interaction, which consists of symbolic structures and its meaning comes to be shared by the people. Objectification is the process by which this production is collectively recognized, accepted and used. This is validated as being reliable and valuable. Internalization is the process by which the objectivated world is perceived as the facts in the course of socialization. Social reality is constructed through these three institutionalization phases. In another way, the institution is formed through the reciprocal habitualized actions. As a member of a group, a person supposes to perform actions and follows the rules. Over time, by following the rules or by performing shared habitual actions, an institution is created. When a new member comes to the group, he realizes the existing institution. Thus, the rules are formed together and subjectively brought into practice. Such subjective rules form the objective institution, which is the identity of the people involved in.

Furthermore, rapidly speeding up media technology, by continuous flows of media products, is compelling to create new social reality both, subjectively and objectively. Berger and Luckmann's analysis of society as a subjective reality describes how our conception of reality originates from our interaction with social structures. Those concepts or inventions become a part of our reality through the process of objectification of the inventions. When these objective realities are institutionalized, they appear as 
a form of culture (Berger and Luckmann, 1966) which is the identity of the people concerned with.

\section{Conclusion}

Identity is a categorization of a person by oneself and by others, which is categorized through the theoretical concept of 'us' and 'them'. Categorization of 'us' and 'them' is based on one's worldview, internal/external forces, degree of sameness and differences and so on. In the process of cultural mixing, there is possibility of cultural homogenization and cultural heterogenization. Similarities make the people nearer to each other which broadens the circle of 'us' and hence can lead toward homogenization of culture between immigrants and host nationals. On the other hand, dissimilarities increase the level of 'them' therefore leads towards heterogenization. Because similar type of worldviews creates similar type of social reality and practicing those realities in similar way leads towards cultural homogenization. In contrast, different types of worldviews create different social reality hence creates different social and cultural norms and behaviors which lead towards cultural heterogenization.

Therefore, immigrants' identity is formed through the interaction among the rapidly increasing global inflows of knowledge; their previous worldviews, the integration activities provided by host countries, feeling of external pressure and so forth. In the process of interaction, the social and cultural patterns of social reality can be emerged, reshaped, even become more strong and broadened. Practicing these in daily life creates social order with reshaped social and cultural norms and values, social and cultural patterns, and behaviors which is the identity of a person or community.

\section{Reference}

Anderson, Benedict (2006). Imagined Communities. New York: Verso Publication.

Appudurai, Arjun. (2002). 'Disjuncture and Difference in the Global Cultural Economy'. Inda, J. X. and Rosaldo, R. (eds) The Anthropology of Globalization A Reader. Pp 47-65. UK: Blackwell.
Barth, Fredrik. (1966). Model of Social organization. London: Royal Anthropological Institute, Occasional papers, no.23. Bauman, Zygmunt. (1998). Globalization. The Human Consequences of Globalization. Minneapolis: University of Minnesota Press.

Beck, Ulrich. (2000). What is Globalization. UK: Polity.

Berger, Peter L. and Luckmann, Thomas (1966). The Social Construction of Reality: A Treatise in the Sociology of Knowledge. Garden City, NY: Anchor Books.

Eriksen, Thomas Hylland (2007). Globalization: The Key Concepts. Yew York:Berg.

Eriksen, Thomas Hylland (2004). What is Anthropology. London: Pluto Press.

Eriksen, Thomas Hylland (2001). Small Places, Large issues: an Introduction Social and Cultural Anthropology ( $2^{\text {nd }}$ edition). Archway Road, Londan: Pluto Press.

Erikson, Erik H. (1950). Childhood and Society. New York: Norton.

Fiske, John (1990). Introduction to Communication Studies (Second Edition). London and New York: Routledge.

Gellner, Ernest (1983). Nations and Nationalism. Oxford:Berg.

Giddens, Anthony (1990). The Consequences of Modernity. Cambridge:Polity.

Gillis, John R. (1994). 'Memory and Identity: The History of Relationship', in John R. G.illis (ed) Commemorations: The Politics of National Identity Pp 3-27. Princeton, NJ: Princeton University Press.

Hiebert, Paul G. (2008). Transforming Worldviews An Anthropological Understanding of how People Change. Michigan: Barker Academic, a division of Barker Publishing Group.

Jenkins, Richard (2008). Social Identity. Routledge.

Meijl, Toon Van (2008). 'Culture and Identity in Anthropology: Reflections on Unity and Uncertainty in the Dialogical Self'. International Journal for Dialogical Science 3(1) 165:190.

Scott, W. Richard (2001). Institutions and Organizations: Foundations for Organizational Science. ( $2^{\text {nd }}$ Ed.). Thousand Oaks, Ca: Sage.

Sharma, Manju (2012). Construction the Way of Life: Bhutanese in Norway. LAMBERT Academic Publishing GmbH \& Co. KG. Stiglitz, Joseph E. (2007). Making Globalization Work. Norton \& Co. 